\title{
Practice patterns in the management of preterm labor in India: a multi- centric, retrospective study
}

\author{
P. B. Jaju' ${ }^{*}$, Abha Sood², Vaishali Chavan³, Geetanjali Devgarha4, Seema Jain ${ }^{5}$, \\ Vinodraj Kundapur ${ }^{6}$, Rashmi Hegde ${ }^{6}$
}

\begin{abstract}
${ }^{1}$ Department of Obstetrics and Gynecology, B. M. Patil Medical College Hospital and Research Centre, Vijayapur, Karnataka, India

${ }^{2}$ Department of Obstetrics and Gynecology, Jaipur Golden Hospital, Delhi, India

${ }^{3}$ Department of Obstetrics and Gynecology, Noble Hospital Pvt Ltd, Pune, Maharshtra, India

${ }^{4}$ Department of Obstetrics and Gynecology, Marudhar Hospital, Jaipur, Rajasthan, India

${ }^{5}$ Department of Obstetrics and Gynecology, Aditya Birla Memorial Hospital, Pune, Maharshtra, India

${ }^{6}$ Medical Science Division, Abbott India Ltd, Mumbai, Maharshtra, India
\end{abstract}

Received: 13 November 2017

Accepted: 16 November 2017

*Correspondence:

Dr. P. B. Jaju,

E-mail: p.b.jaju@gmail.com

Copyright: (c) the author(s), publisher and licensee Medip Academy. This is an open-access article distributed under the terms of the Creative Commons Attribution Non-Commercial License, which permits unrestricted non-commercial use, distribution, and reproduction in any medium, provided the original work is properly cited.

\begin{abstract}
Background: Preterm labor (PTL) is considered as one of the leading cause of perinatal morbidity and mortality. Preterm labor refers to the onset of uterine contractions of sufficient strength and frequency to effect progressive dilatation and effacement of cervix between 22 and 37 weeks of gestation.

Methods: In this study, 285 patients of PTL admitted/treated (during the period of $1^{\text {st }}$ January 2014 to $31^{\text {st }}$ December 2016) across 5 centres in India were enrolled. Adult women with PTL, receiving oral or intravenous regime of tocolytic drugs were screened based on eligibility criteria.

Results: We evaluated the practice patterns in the management of PTL in India. The pharmacological management $(n=193)$ was preferred over nonpharmacological management $(n=92)$ in the present study. Amongst the pharmacological agents, isoxsuprine $(60.10 \%)$ was more frequently used followed by nifedipine $(23.83 \%)$. Prolongation of delivery for at least 48 hours was observed in $57.76 \%$ patients receiving isoxsuprine compared to $34.78 \%$ patients receiving nifedipine. The mean latency period $(36.77 \pm 28.09$ vs. $1.44 \pm 1.33$ days $)$, birthweight $(2.25 \pm 1.34$ vs. $1.07 \pm 0.34 \mathrm{~kg})$ and Apgar score at 5 mins $(7.56 \pm 2.36$ vs. $4.87 \pm 2.10)$ was higher for isoxsuprine compared to nifedipine group patients, with mean gestational age of <32 weeks (extreme to very PTL cases; $\mathrm{p}<0.0001)$. Similar results were observed in latency period and Apgar score between isoxsuprine and nifedipine groups in late PTL cases ( $>32$ weeks).

Conclusions: Pharmacological treatment was preferred for the management of PTL in India. Among pharmacological agents, isoxsuprine was preferred over other tocolytics. Significant improvement in mean latency period, prolongation of delivery beyond 48 hours and perinatal outcomes were noted amongst patients on isoxsuprine versus other pharmacological agents.
\end{abstract}

Keywords: Isoxsuprine, Latency period, Nifedipine, Preterm labor, Pregnancy prolongation, Tocolytics 


\section{INTRODUCTION}

Preterm labor (PTL) is defined as regular contractions associated with cervical changes before completion of 37 weeks of gestation, by American College of Obstetricians and Gynaecologists (ACOG). ${ }^{1}$ The incidence of preterm labor is $23.3 \%$ and of preterm delivery is $10-69 \%$ in India. $^{2}$ This incidence of preterm labor and preterm delivery may vary widely based on populations; risk factors such as low maternal pre-pregnancy weight, socioeconomic status, racial and ethnic factors; maternal education; maternal work patterns; physical effort during pregnancy, especially, third trimester; maternal sexual activity; tobacco use; interval between pregnancies; uterine abnormalities etc. ${ }^{3}$ Preterm delivery also accounts for about $40-75 \%$ of neonatal deaths, making it one of the leading causes of perinatal morbidity and mortality. ${ }^{2}$

Long-term morbidity comprises of cerebral palsy, neurodevelopmental delay and chronic lung disease. Generally, the neonatal outcome is associated with gestational age at delivery and other elements such as infection. Earlier data suggests that lower gestational age is related with higher risk of mortality and morbidity. Treatment for PTL consists of identification of high-risk women, prevention and treatment. ${ }^{4}$

However, identification of women at high risk for preterm delivery remains a major challenge. The prediction of onset of PTL includes associated risk factors, Home Uterine Activity Monitoring (HUAM), Salivary Estriol, screening for Bacterial Vaginosis (BV), screening for Fetal Fibronectin (FFN), and cervical ultrasonography (cervical length assessment). One of the major associated risk factor is the previous history of PTL. The incidence of PTL in subsequent pregnancies after one preterm birth increases to $14.3 \%$ and after two preterm births, it rises to $28 \%$. Other risk factors include multiple pregnancy, cigarette smoking, cervical incompetence or uterine anomalies, uterine overdistension (polyhydramnios, macrosomia, and fibroids), previous cervical surgery, using smokeless tobacco, bleeding in early pregnancy, bacterial vaginosis, poor socioeconomic or educational status, and young or advanced maternal age. Although many approaches have been used to predict preterm delivery, the success rate is less, even in high-risk women. ${ }^{5}$

Lack of effective methods to predict/prevent PTL has shifted the focus to the treatment of the woman admitted for PTL. ${ }^{6}$ According to ACOG, the goal of management of PTL is to provide prophylactic pharmacological treatment in order to delay delivery, decrease infection in mother and prevent respiratory distress in new-borns. Hence, presently, the treatment for PTL revolves primarily around the use of tocolytics, corticosteroids, antibiotics and other supportive care. ${ }^{7}$ The commonly used tocolytics are Beta-2 agonists (isoxsuprine hydrochloride, terbutaline sulfate and ritodrine hydrochloride), calcium channel blockers (nifedipine), oxytocin receptor antagonists (atosiban), prostaglandin synthetase inhibitors, magnesium sulfate and nitric oxide donors. $^{8-10}$ They act through various mechanisms to decrease the availability of intracellular calcium ions, leading to inhibition of actin-myosin interaction. ${ }^{5}$

Pertinently, the management of PTL has been plagued by a low success rate along with the incidence of serious side-effects arising from the use of therapeutic approaches, more so with beta-mimetic tocolytics. Hence, given the enormity of the burden posed by PTL on human society, a closer scrutiny of the current clinical management practices of PTL is not bereft of scientific merit. Moreover, the data with regards to the clinical practice patterns in the management of PTL among the Indian population is scarce. Hence, the present study was carried out to evaluate the existing trends in the clinical management practices of PTL amongst Indian women.

\section{METHODS}

Case records of 285 women with spontaneous PTL (2437 weeks of gestation), as diagnosed by the physician, admitted/treated between $1^{\text {st }}$ January 2014 to $31^{\text {st }}$ December 2016, across 5 centres in India, were included for evaluation in this multicentric, retrospective study. Since this was retrospective data collection study, informed consent from patients was not applicable. Patients with known short cervix maintained on tocolytics, with preterm premature rupture of membranes, triplet and higher-order multifetal pregnancy, and those with a fetal structural or genetic anomaly, with incomplete hospital records were excluded from the study. Data on demographics, obstetric history/profile, pharmacological interventions, pregnancy and foetal outcome, and safety aspects were collected.

The primary intent of this retrospective study was to assess the clinical and obstetric characteristics of patients with PTL in terms of maternal age, gravidity, type of gestation (primiparous/multiparous), gestational age on admission, cervical dilatation, cervical effacement and uterine contraction frequency. Percentage of patients receiving different pharmacological agents used for the management of PTL was also assessed. The secondary intent was the percentage of patients who underwent pharmacological and non-pharmacological management practice for PTL. Success rate of different pharmacological treatment for PTL (in terms maternal and perinatal outcome) and the percentage of patients with adverse effect as observed/reported with the use of different pharmacological treatments were also assessed.

\section{Statistical analysis}

All statistical analyses were performed using a two-sided hypothesis test at the overall $5 \%$ level of significance. Discrete data was summarized using frequency counts (n) and percentages $(\%)$. Continuous data was summarized using number $(\mathrm{n})$, mean along with standard deviation (in 
case of normal distribution) or median with minimum and maximum/interquartile range (in case of skewed data distribution). For ordinal-scaled variables, a combination of the above was employed as appropriate: frequency and percentage of observations within a category and mean along with standard deviation (in case of normal distribution) or median with minimum and maximum/interquartile range (in case of skewed data distribution). Chi-squared test was used for discrete and ordinal data and analysis of variance (ANOVA) for normally distributed data or Kruskal-Wallis test. The pvalue was calculated using Chi square test statistics for both the major groups.

\section{RESULTS}

Data from 285 women were included in this retrospective analysis. The mean age of the study population was $26.28 \pm 4.62$ years. Majority of women $(62.11 \%)$ were with BMI of above $25 \mathrm{~kg} / \mathrm{m}^{2}$.

Out of 285 patients, $187(65.6 \%)$ had some significant medical history, i.e: $65.6 \%$ patients with comorbidities were on tocolytics. Hypertension (77 [27.02\%]), followed by previous preterm delivery history (67 [23.51\%]) were the most commonly reported comorbidities.

Table 1: Clinical and obstetric characteristics of all patients.

\begin{tabular}{|c|c|c|}
\hline Characteristics & & Total $(\mathrm{N}=\mathbf{2 8 5})$ \\
\hline Mean average gestational age at onset of preterm labor (weeks) & & $32.78 \pm 3.12$ \\
\hline Mean average gestational age at preterm delivery (weeks) & & $34.05 \pm 3.06$ \\
\hline \multirow{2}{*}{ Gravidity, n (\%) } & Primigravidae & $140(49.12 \%)$ \\
\hline & Multigravidae & $145(50.88 \%)$ \\
\hline \multirow{2}{*}{ Parity, n (\%) } & Primiparae & $166(58.25 \%)$ \\
\hline & Multiparae & $119(41.75 \%)$ \\
\hline Mean average frequency of uterine contractions ( 30 minutes) & & $3.49 \pm 3.49$ \\
\hline Cervical dilatation $(\mathrm{cm})$ & & $2.16 \pm 3.72$ \\
\hline \multirow{4}{*}{ Cervical effacement, n (\%) } & $0-30 \%$ & $189(66.32 \%)$ \\
\hline & $40-50 \%$ & $44(15.43 \%)$ \\
\hline & $60-70 \%$ & $19(6.67 \%)$ \\
\hline & $\geq 80 \%$ & $33(11.58 \%)$ \\
\hline
\end{tabular}

Out of $285,140(49.12 \%)$ were primigravida, while remaining $145(50.88 \%)$ were multigravida. More than half of the patients (166 [58.25\%]) were primipara; 119 $(41.75 \%)$ were multipara (Table 1$)$.

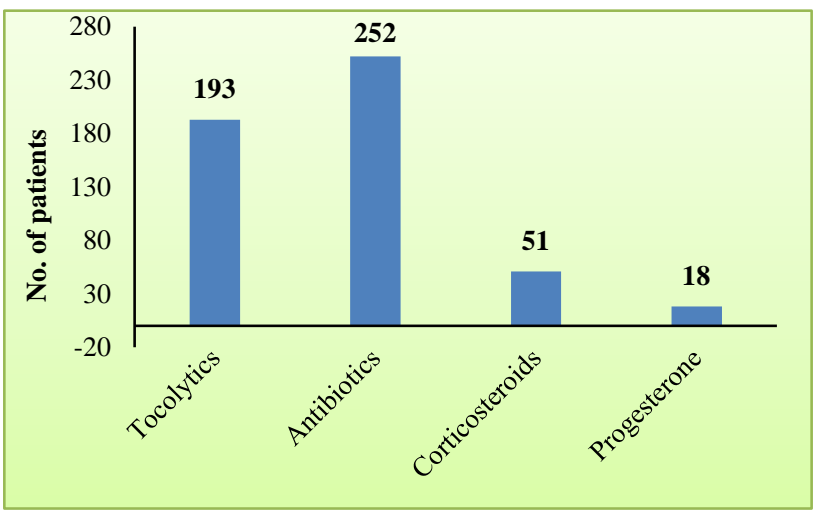

Figure 1: Pharmacological agents in management of preterm labor.

In this study, it was found that pharmacological treatment was preferred for the management of PTL in majority of the cases over nonpharmacological treatment $(68 \%$ vs. $32 \%)$. Out of various pharmacological agents, 193 $(67.72 \%)$ patients received tocolytics, 252 (88.42\%) received antibiotics, $51 \quad(17.90 \%)$ received corticosteroids, and $18(6.67 \%)$ received progesterone (Figure 1). Out of 193 (67.72\%) patients on tocolytics, majority received isoxsuprine alone [116 (60.10\%)] followed by nifedipine $46(23.83 \%)$ (Figure 2$)$.

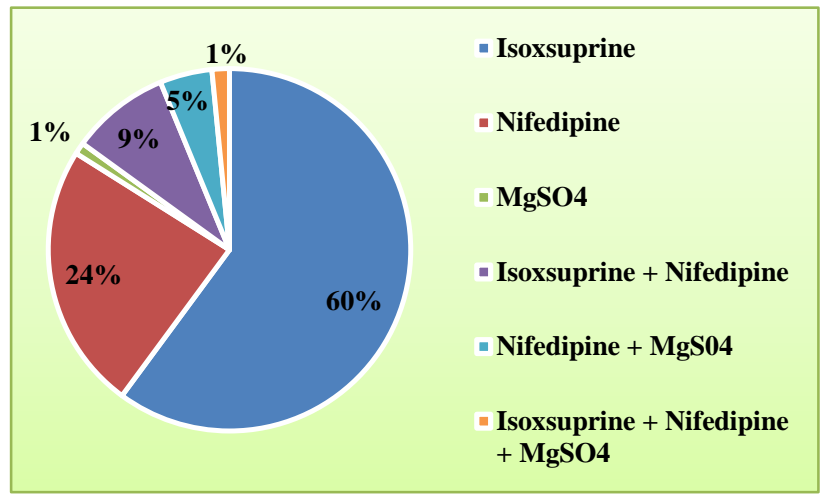

Figure 2: Preterm labor management with tocolytics.

Maternal and perinatal outcome with pharmacological treatment was better compared to non-pharmacological treatment. Patients on pharmacological treatment presented with lesser cervical dilatation at the time of admission compared to nonpharmacological treatment $(\mathrm{p}=0.003)$. 
In pharmacological treatment group, $125(64.77 \%)$ patients had less than $30 \%$ cervical effacement, 48 $(24.87 \%)$ had $40-70 \%$ cervical effacement and 20 $(10.36 \%)$ patients had more than $80 \%$ cervical effacement. There was a significant difference in the mean latency period between pharmacological versus nonpharmacological treatment group $(\mathrm{p}<0.0001)$.
Mean birth weight was $2.17 \pm 1.66 \mathrm{~kg}$ in pharmacological treatment group which was higher compared to mean birth weight of $1.75 \pm 0.66 \mathrm{~kg}$ in nonpharmacological treatment group. Mean Apgar score was higher at $1 \mathrm{~min}$ and at 5 mins in pharmacological treatment compared to nonpharmacological treatment group (Table 2).

Table 2: Patients receiving pharmacological and non-pharmacological treatment.

\begin{tabular}{|llll|}
\hline Characteristics & & Pharmacological (n=193) & Non-pharmacological (n=92) \\
\hline Cervical dilatation (cms) & & $1.71 \pm 1.76$ & $3.08 \pm 5.92$ \\
& $0-30 \%$ & $125(64.77 \%)$ & $64(69.57 \%)$ \\
Cervical effacement (\%) & $40-50 \%$ & $35(18.13 \%)$ & $9(9.78 \%)$ \\
& $60-70 \%$ & $13(6.74 \%)$ & $6(6.52 \%)$ \\
\cline { 2 - 4 } & $\geq 80 \%$ & $20(10.36 \%)$ & $13(14.13 \%)$ \\
\hline Mean latency period (days) & & $13.95 \pm 21.87$ & $1.52 \pm 6.56$ \\
\hline Mean birth weight (kg) & & $2.17 \pm 1.66$ & $1.75 \pm 0.66$ \\
\hline Mean Apgar score & At 1 min & $6.36 \pm 1.90$ & $4.04 \pm 2.81$ \\
\hline NICU admission & At 5 mins & $7.48 \pm 2.39$ & $4.79 \pm 3.46$ \\
\hline
\end{tabular}

Out of 116 patients who received isoxsuprine, we found that 66 patients received injections followed by oral dose (maximum combined daily dose up to $60 \mathrm{mg}$ ). Patients receiving only oral dose of isoxsuprine $(n=50)$ got maximum daily dose up to $40 \mathrm{mg}$ for an average of $23.01 \pm 23.55$ days. For patients who received nifedipine, the average number of days of administration was $5.17 \pm 8.75$ days; maximum number of patients $(n=36)$ received less or equal to $30 \mathrm{mg}$ daily dose whereas 10 patients received more than $30 \mathrm{mg}$ dose. On comparison between patients receiving tocolytics in relation to their cervical dilatation $(<2 \mathrm{~cm}$ and $>2 \mathrm{~cm})$, it was found that there was no patient who received $\mathrm{MgSO} 4$ and was cervically dilated for more than $2 \mathrm{~cm}$. Mean latency period in isoxsuprine group with cervical dilatation of $<2$ cms was higher $(25.09 \pm 26.02$ days $)$ compared to the patients in nifedipine group, with cervical dilatation of $<2$ $\mathrm{cm}$ (4.90 \pm 8.86 days). Similar results were obtained in patients with cervical dilatation of $>2 \mathrm{cms}(8.11 \pm 18.39$ days versus $1.15 \pm 1.28$ days).

Table 3: Prolongation of delivery after receiving tocolytics $(n=193)$.

\begin{tabular}{|c|c|c|c|c|c|c|}
\hline Characteristics & $\begin{array}{l}\text { Isoxsuprine } \\
(\mathrm{n}=116)\end{array}$ & $\begin{array}{l}\text { Nifedipine } \\
(\mathrm{n}=46)\end{array}$ & $\begin{array}{l}\mathrm{MgSO}_{4} \\
(\mathrm{n}=2)\end{array}$ & $\begin{array}{l}\text { Isoxsuprine+ } \\
\text { Nifedipine } \\
(\mathbf{n}=17)\end{array}$ & $\begin{array}{l}\text { Nifedipine+ } \\
\mathrm{MgSO}_{4} \\
(\mathrm{n}=9)\end{array}$ & $\begin{array}{l}\text { Isoxsuprine+ } \\
\text { Nifedipine+ } \\
\mathrm{MgSO}_{4}(\mathrm{n}=3)\end{array}$ \\
\hline $\begin{array}{l}\text { Prolongation of delivery } \\
\text { beyond } 48 \mathrm{hrs}\end{array}$ & $67(57.76 \%)$ & $16(34.78 \%)$ & $1(50 \%)$ & $9(52.94 \%)$ & $1(11.11 \%)$ & $2(66.67 \%)$ \\
\hline
\end{tabular}

Table 4: Maternal outcomes in relation with gestational age.

\begin{tabular}{|c|c|c|c|c|c|c|c|c|}
\hline $\begin{array}{l}\text { Character- } \\
\text { istics }\end{array}$ & $\begin{array}{l}\text { Gestational } \\
\text { age at onset of } \\
\text { preterm labor }\end{array}$ & $\begin{array}{l}\text { Isoxsuprine } \\
(\mathrm{n}=116)\end{array}$ & $\begin{array}{l}\text { Nifedipine } \\
(\mathrm{n}=46)\end{array}$ & $\begin{array}{l}\mathrm{MgSO}_{4} \\
(\mathrm{n}=2)\end{array}$ & $\begin{array}{l}\text { Isoxsuprine+ } \\
\text { Nifedipine } \\
(\mathbf{n}=17)\end{array}$ & $\begin{array}{l}\text { Nifedipine+ } \\
\mathrm{MgSO}_{4} \\
(\mathrm{n}=9)\end{array}$ & $\begin{array}{l}\text { Isoxsuprine+ } \\
\text { Nifedipine+ } \\
\mathrm{MgSO}_{4} \\
(\mathrm{n}=3)\end{array}$ & P value \\
\hline \multirow{2}{*}{$\begin{array}{l}\text { Mean } \\
\text { Latency } \\
\text { period(days) }\end{array}$} & $<32$ weeks & $36.77 \pm 28.09$ & $1.44 \pm 1.33$ & $1.50 \pm 0.70$ & - & $0.50 \pm 0.70$ & $4 \pm 0.00$ & $<0.0001$ \\
\hline & $>32$ weeks & $11.20 \pm 17.61$ & $4.43 \pm 8.48$ & - & $3.43 \pm 3.93$ & $0.71 \pm 0.75$ & - & 0.011 \\
\hline
\end{tabular}

Prolongation of delivery for at least 48 hours was reported in $57.69 \%$ patients receiving isoxsuprine versus $34.78 \%$ patients receiving nifedipine, giving sufficient time for maximal beneficial effect of corticosteroids in those it was administered (Table 3 ). 
Mean latency period in extreme to very pre-term cases (<32 weeks) was higher in isoxsuprine group (36.77 \pm 28.09 days) compared to patients in nifedipine group (1.44 \pm 1.33 days); similar results were obtained in patients with moderate to late pre-term cases $(>32$ weeks; $11.20 \pm 17.61$ days in isoxsuprine group versus $4.43 \pm 8.48$ days in nifedipine group) (Table 4$)$.

Mean birth weight and mean Apgar score with respect to pre-term classification ( $<32$ weeks or $>32$ weeks) were also compared between isoxsuprine and nifedipine groups. The mean birthweight in patients with mean gestational age of $<32$ weeks was higher in isoxsuprine group compared to patients in nifedipine group $(2.25 \pm 1.34 \mathrm{~kg}$ versus $1.07 \pm 0.34 \mathrm{~kg}$; $\mathrm{p}<0.0001)$. Furthermore, mean Apgar score at 5 mins with gestational age of $<32$ weeks was also significantly higher in isoxsuprine group patients compared to nifedipine group $(\mathrm{p}<0.0001)$; however, no significant difference was found between isoxsuprine and nifedipine groups in mean Apgar score at 1 mins. Overall among patients receiving pharmacological management for PTL, there was an increase in gestation period with favourable pregnancy outcome in those receiving isoxsuprine (Table 5).

Table 5: Perinatal outcomes in relation with gestational age.

\begin{tabular}{|c|c|c|c|c|c|c|c|c|c|}
\hline \multicolumn{2}{|c|}{ Characteristics } & $\begin{array}{l}\text { Gestational } \\
\text { age at onset } \\
\text { of preterm } \\
\text { labor }\end{array}$ & $\begin{array}{l}\text { Isoxsuprine } \\
(\mathrm{n}=116)\end{array}$ & $\begin{array}{l}\text { Nifedipine } \\
(\mathrm{n}=\mathbf{4 6})\end{array}$ & $\begin{array}{l}\mathrm{MgSO}_{4} \\
(\mathrm{n}=2)\end{array}$ & $\begin{array}{l}\text { Isoxsuprine } \\
\text { +Nifedipine } \\
(\mathrm{n}=17)\end{array}$ & $\begin{array}{l}\text { Nifedipine } \\
+\mathrm{MgSO}_{4} \\
(\mathrm{n}=9)\end{array}$ & $\begin{array}{l}\text { Isoxsuprine } \\
+ \text { Nifedipine } \\
\text { +MgSO }_{4} \\
(n=3)\end{array}$ & $P$ value \\
\hline \multirow{2}{*}{\multicolumn{2}{|c|}{$\begin{array}{l}\text { Mean birth } \\
\text { weight }\end{array}$}} & $<32$ weeks & $2.25 \pm 1.34$ & $1.07 \pm 0.34$ & $1.34 \pm 0.21$ & - & $1.10 \pm 0.14$ & $0.95 \pm 0.07$ & $<0.0001$ \\
\hline & & $>32$ weeks & $2.25 \pm 0.50$ & $2.50 \pm 3.32$ & - & $1.94 \pm 0.40$ & $1.84 \pm 0.70$ & - & 0.43 \\
\hline \multirow{4}{*}{$\begin{array}{l}\text { Mean } \\
\text { Apgar } \\
\text { score }\end{array}$} & \multirow{2}{*}{$\begin{array}{l}1 \\
\min \end{array}$} & $<32$ weeks & $4.87 \pm 2.10$ & $4.55 \pm 1.42$ & $2.50 \pm 3.53$ & - & $2 \pm 2.82$ & $3.50 \pm 0.70$ & 0.344 \\
\hline & & $>32$ weeks & $7.01 \pm 1.44$ & $6.35 \pm 1.73$ & - & $6.37 \pm 1.15$ & $4.57 \pm 1.81$ & - & 0.014 \\
\hline & \multirow{2}{*}{$\begin{array}{l}5 \\
\operatorname{mins}\end{array}$} & $<32$ weeks & $7.56 \pm 2.36$ & $4.87 \pm 2.10$ & $2.50 \pm 3.53$ & - & $6.87 \pm 2.09$ & $6.28 \pm 1.97$ & $<0.0001$ \\
\hline & & $>32$ weeks & $8.34 \pm 1.93$ & $7.43 \pm 2.27$ & - & - & $2.0 \pm 2.82$ & - & 0.011 \\
\hline
\end{tabular}

Out of 18 patients who received progesterone (intramuscular route) in combination with tocolytics, 15 received progesterone with isoxsuprine, 2 received with nifedipine and 1 received with MgSO4. When progesterone was administered with isoxsuprine, mean latency period (52.26 \pm 28.86 days) was higher compared to progesterone plus nifedipine combination (22.50 \pm 13.43 days). However, sample size was not powered enough to substantiate the efficacy of this combination.

No adverse events were recorded in medical records.

\section{DISCUSSION}

The cause for preterm birth in many situations is elusive and unknown. Though significant development has been made in the care of premature infants, the prevalence of preterm birth has not been reduced. According to ACOG, the goal of management of PTL is to provide prophylactic pharmacological treatment in order to delay delivery, decrease infection in mother and prevent respiratory distress in newborns. ${ }^{11}$

Cochrane review (2003) published on PTL suggested that tocolytics are indicated before 34 weeks' gestational age, with reduction in number of women delivering within subsequent 7 days, and thus decrease in neonatal morbidity. ${ }^{12}$ The treatment of women at risk of preterm delivery consists of administration of tocolytic drugs in order to delay labor for 48 hours to facilitate for administration of corticosteroids and transportation of the patient to a center with NICU facilities especially if gestational age is $<32$ weeks. $^{13}$

Isoxsuprine, which is a beta-adrenergic agonist and a potent vasodilator, was actually the first drug to be published as a tocolytic agent to prevent uterine contractions. $^{14,15}$ ACOG recommends beta adrenergic drugs as a first line tocolytic agents in the management of PTL. ${ }^{16}$ However, ACOG also recommends calcium channel blockers, or NSAIDs for short-term prolongation of pregnancy (up to 48 hours). ${ }^{16}$

Isoxsuprine is also approved by CDSCO for the management of PTL. ${ }^{17} \mathrm{~A}$ number of clinical trials have shown good therapeutic efficacy of isoxsuprine in patients at risk of PTL and risk of abortion, including evidence of good tolerability when used for acute (intravenous) and maintenance (oral or intramuscular administration) therapy. ${ }^{14,15}$

Magnesium sulfate has been widely used during the last half century in a range of doses, both for tocolysis and for seizure prophylaxis in women with preeclampsia. ${ }^{18}$ It is better tolerated, but the patient has to be monitored for toxic effects, such as respiratory depression or even cardiac arrest, which can occur at supertherapeutic levels. Common maternal side effects include flushing, nausea, headache, drowsiness, and blurred vision. Magnesium 
crosses the placenta and causes respiratory and motor depression in the neonate. ${ }^{19}$

Calcium channel blocker, nifedipine, has been used as a first line tocolytic for the management of PTL, despite the proven lack of efficacy. ${ }^{20-23}$ However, in India, the use of nifedipine has not been approved by Central Drug Standard Control Organization (CDSCO) for the management of PTL. ${ }^{24}$ Nevertheless, the innovator has confirmed in an expert opinion published in 2014 that nifedipine has not been licensed for use in PTL or in pregnancy. ${ }^{23}$

In the present study, we evaluated the practice patterns in the management of PTL in India. In our study, patients received tocolytics such as isoxsuprine, nifedipine and $\mathrm{MgSO}_{4}$ for management of PTL. Along with tocolytics, patients also received antibiotics to prevent infection, corticosteroid injections for fetal lung maturity and progesterone as a supportive therapy for PTL management.

A meta-analysis including 16 clinical trials showed a positive effect of tocolytics (beta-agonists) in the delay of PTL. The observations reported in the present study also confirmed the results from the above meta-analysis. ${ }^{25}$ Isoxsuprine was the most frequently used tocolytic in the present study. Overall among patients receiving pharmacological management for PTL, there was an increase in gestation period with favourable pregnancy outcome in those receiving isoxsuprine. The prolongation of delivery beyond 48 hours was also significantly higher in isoxsuprine group than nifedipine group. Better maternal and perinatal outcomes were also reported in patients receiving isoxsuprine compared to patients receiving nifedipine. Isoxsuprine was better tolerated and no adverse event was reported in patients given this tocolytic. Keeping in mind the efficacy and tolerability of isoxsuprine, the potential benefit of isoxsuprine when administered with corticosteroids would be worth evaluating in management of PTL.

When supportive therapy, progesterone (IM), was given along with the tocolytic, isoxsuprine, maternal outcome was significantly improved. However, the sample size was not powered enough to substantiate the efficacy of this combination. Further studies are required to substantiate this data as long term safety of progesterone is yet to be proven. ${ }^{26}$

The results of this retrospective multicentre study have provided baseline data on practice patterns for PTL. However, this study has few limitations. First, being a retrospective data collection study, there can be a possibility of non-capture of certain information due to differences in the accuracy or completeness of the recollections by study participants regarding adverse events or medical history from the past. Second, no adverse events were documented as the data captured was dependent on availability of medical records for the patients. Third, in a multi-centric, retrospective study, there can be a possibility of medical records differing between institutions, as the collection of uniformed patient data was difficult.

\section{CONCLUSION}

Present study suggested the PTL can be managed more effectively by pharmacological treatment than nonpharmacological treatment.

The study findings confirm that, among pharmacological agents, isoxsuprine is more effective in prolonging pregnancy beyond 48 hours, and has also shown better improvements in maternal and perinatal outcomes (latency period, Apgar score, mean birth weight and reduction in NICU admissions). Isoxsuprine as a tocolytic has been found to be reassuring in view of the increasing evidence of its efficacy and safety. However, further efforts are needed in order to develop standardized practice guidelines for PTL management in India.

\section{Funding: Abbott India Ltd}

Conflict of interest: Dr. Jaju, Dr. Sood, Dr. Chavan, Dr. Devgarha and Dr. Jain has received research funding from Abbott India Ltd as a consultant. Dr. Kundapur and Dr. Hegde are employees of Abbott India Ltd.

Ethical approval: The study was approved by the Institutional/Independent Ethics Committee

\section{REFERENCES}

1. ACOG. ACOG Practice Bulletin No. 31: assessment of risk factors for preterm birth. Obstet Gynecol. 2001;98(4):709-716.

2. Sukladas S, Prasad US. A prospective study to assess the neonatal mortality and morbidity associated with preterm labor and delivery in a tertiary care hospital. Ann Int Med Den Res. 2016;2(2):116-9.

3. Egbe TO, Nana Njamen T, Halle Ekane G, Tsingaing JK, Tchente CN, Beyiha G, et al. Outcome of late second trimester emergency cerclage in patients with advanced cervical dilatation with bulging amniotic membranes: a report of six cases managed at the douala general hospital, Cameroon. ISRN Obstet Gynecol. 2013;2013:843158.

4. Chatterjee J, Gullam J, Vatish M. The management of preterm labor. Arch Dis Child Fetal Neonatal Ed. 2007;92:F88-F93.

5. Chandraharan E, Arulkumaran S. Recent advances in management of preterm labor. J Obstet Gynecol India. 2005;55(2):118-24.

6. Hass DM, Benjamin T, Sawyer R, Quinney SK. Short-term tocolytics for preterm delivery: current perspectives. Int J Women's Health. 2014;6:343-9.

7. Schleußner E. The prevention, diagnosis and treatment of premature labor. Dtsch Arztebl Int. 2013;110(13):227-36. 
8. Bellad MB, Dhumale H and Shravage JC. Preterm labor: a review. South Asian Federation Obstet Gynecol. 2009;1(3):1-4.

9. Haas DM, Caldwell DM, Kirkpatrick P, McIntosh JJ, Welton NJ. Tocolytic therapy for preterm delivery: systematic review and network meta-analysis. BMJ. 2012;345:e6226.

10. Pradyuman V, Mekhla G. A comparative study of two tocolytic agents for inhibition of preterm labor. Gujarat MedJ. 2014;69(1):28-31.

11. Devi PK, Krishna Menon MK, B Bhasker Rao K. Postgraduate Obstetrics and Gynecology. $3^{\text {rd }}$ Ed. Chennai: Orient Longman Ltd;1980:204-9.

12. King JF, Flenady VJ, Papatsonis DNM. Calcium channel blockers for inhibiting preterm labor (Cochrane review). Cochrane Database Syst Rev. 2003;1:CD002255.

13. van Vliet EO, Boormans EM, de Lange TS, Mol BW, Oudijk MA. Preterm labor: current pharmacotherapy options for tocolysis. Expert Opin Pharmacother. 2014;15:787-97.

14. Giorgino FL, Egan CG. Use of isoxsuprine hydrochloride as a tocolytic agent in the treatment of preterm labor: a systematic review of previous literature. Arzne Im It Telforschung. 2010;60(7):415420.

15. Mahajan A, Marwah P. Isoxsuprine as a tocolytic agent in preterm labor. Int $\mathrm{J}$ Basic Appl Med Sci. 2015;5(3):86-91.

16. ACOG. ACOG Practice Bulletin No. 171: Management of preterm labor. Obstet Gynecol. 2016; 128(4):e155-e164.

17. National Formulary of India (2011). Available at http://www.cdsco.nic.in/writereaddata/NFI_2011\%2 0(1).pdf. Accessed on September 22, 2017.
18. Rodriguez MI. The role of magnesium sulfate in preterm labor: a best evidence review. Medscape. Dec 04, 2009.

19. Peter S Bernstein, Mary King. Using nifedipine as a tocolytic in preterm labor. Medscape. Aug 18, 2004.

20. Ananth CV, Vintzileos AM. Epidemiology of preterm birth and its clinical subtypes. J MaternalFetal Neonatal Med. 2006;19(12):773-82.

21. Bina I, Parveen T, Khanom A, Shamsunnahar PA. The tocolytic role of nifedipine in preventing preterm labor pain. Mymensingh Med J. 2012;21(1):139-44.

22. Conde-Agudelo A, Romero R, Kusanovic JP. Nifedipine for the management of preterm labor: A systematic review and metaanalysis. Am J Obstet Gynecol. 2011;204(2):134.e1-134.20.

23. Jørgensen JS, Weile LK, Lamont RF. Preterm labor: current tocolytic options for the treatment of preterm labor. Expert Opin Pharmacother. 2014;15(5):585-8.

24. Indian consensus document on isoxsuprine. revisiting the use of isoxsuprine in preterm labor. Indian Society for the Study of Reproduction and Fertility (ISSRF). Elsevier. 2017

25. King JF, Grant A, Keirse MJ. Beta-mimetics in preterm labour: An overview of randomized controlled trials. Br J Obstey Gynecol. 1988;93:21122.

26. ACOG Committee Opinion. Use of progesterone to reduce preterm birth. Obstet Gynecol. 2003 Nov;102 (5 Pt 1):1115-6.

Cite this article as: Jaju PB, Sood A, Chavan V, Devgarha G, Jain S, Kundapur V et al. Practice patterns in the management of preterm labor in India: a multi-centric, retrospective study. Int J Reprod Contracept Obstet Gynecol 2017;6:5306-12. 